\title{
The International Public Procurement Evolution: New Strategic Challenges Met in Collaboration with Internal Audit Advisory Services
}

\section{Georgios Baltos}

\author{
Ph.D(c) of Business School, \\ University of the Aegean, Chios, Greece
}

\section{Leonardo Doni}

MA in International relations and European Studies, University of Florence, Italy

\author{
Janis Balodis \\ Belarusian Economic Research and \\ Outreach Center (BEROC), Minsk, Belarus
}

Doi: 10.2478/ajis-2018-0020

\begin{abstract}
This study identifies and evaluates some of the major procurement issues met currently by international organizations both in private and public sectors. It deals with strategic procurement decision-making like outsourcing and market globalization, concessions set up, business continuity and contracting typology transformations. Such dynamic changes are deployed in a context of increased concern about the application of liberal procurement principles, which drive towards a series of improvements at the procedures and documentation level. The authors relate this evolution with the Internal Audit consulting perspective, which is still a recent endeavor, but in progress and dynamically expanding. European Union and related Agencies and Institutions are usually spearheading towards this direction offering lessons learned for further consideration.
\end{abstract}

Keywords: Procurement consulting; Internal Audit; outsourcing; framework contracts; contracting typology

\section{Introduction}

The latest definition of Internal Auditing (IA) describes its function "as an independent, objective assurance and consulting activity aimed to add value and improve an organization's operations" (Corinna Boecker et al. 2008). Despite the numerous differences in viewpoints, a sharp shift has occurred in the nature of internal audit towards a more interactive and comprehensive engagement in the evaluation of the operational activities (Nagy at al. 2002). At the same time, plenty of experts and market analysts highlighted the added value and the advantages stemming out of procurement advisory. This is mainly because, as F. den Butter and K. Linse (Den Butter et al. 2008) state, although purchasing and contracting transactions along with their costs are fully identified and classified for every stage of a procurement life cycle, the benefits of this detailed documentation may not be practically realized because of unexpected non-compliance issues, complexities and irregularities that appear "uninvited" during the acquisition process. Therefore, taking in consideration the today's global market needs and peculiarities, while procurement compliance 
seems more important than ever, it needs governance and risk-based control management. These aspects can be comprehensively and effectively provided by internal auditors through their consulting services (Alpigiano et al. 2017).

However, IA activities turn their focus on an integrated approach to risk management, not only as a result of the changes in the public and private sector regulatory requirements, but also in an effort to release the auditors' creativity and usefulness, upgrading their status into a trusted advisor's level (Jedrzejowicz et al. 2010). It is accurate that in the past internal audit had focused primarily on identifying policy violations and noncompliance with regulations. Thus, the relevant auditors' job descriptions are being transformed so they can also offer auditors and their clients the needed leeway to promote trust in the dynamically changing field of contracting and procurement (Aschauer et al. 2017). The professional field of the internal auditor's engagements is consequently being expanded. The transition from the past to the present audit terminology depicts the new orientation lines; the new approach is characterized by a swift from correction to prevention, from accounting focus to organizational added value, comprehensive support, collaborative attitude, holistic approach and insightful advisory (Lember et al. 2013).

\section{Methodological Approach of the Procurement Advisory}

Given the size and significance of EU acquis on public procurement, the latter can be considered a driver for model procedures, "know how" and best practices applied in this field. This study is highly based on EU related contracting review and lessons learned. The EU approach is indeed systemically ideal since it refers holistically to the process by which public authorities, mostly government departments and local authorities, purchase goods, works and services from contractor companies, setting out a minimum of harmonized public procurement rules resulting though in maximum level of effectiveness (Bovis 2012).

The lifecycle of public procurement is anyway multi-layered covering broad dimensions like the internal procurement organization and its impact on the external business environment, while the core influencers of the procurements management may be governing bodies and top management, executive procurement management as well as internal auditors, reviewers and advisors offering advice and support. The schema below (Figure 1) snapshots a "mechanism" of integrated activities and engagements, where the design of the governance structure of procurements does not have a mechanistic or stagnantly bureaucratic character, but aims to recycle relevant and practical information for the stakeholders involved.

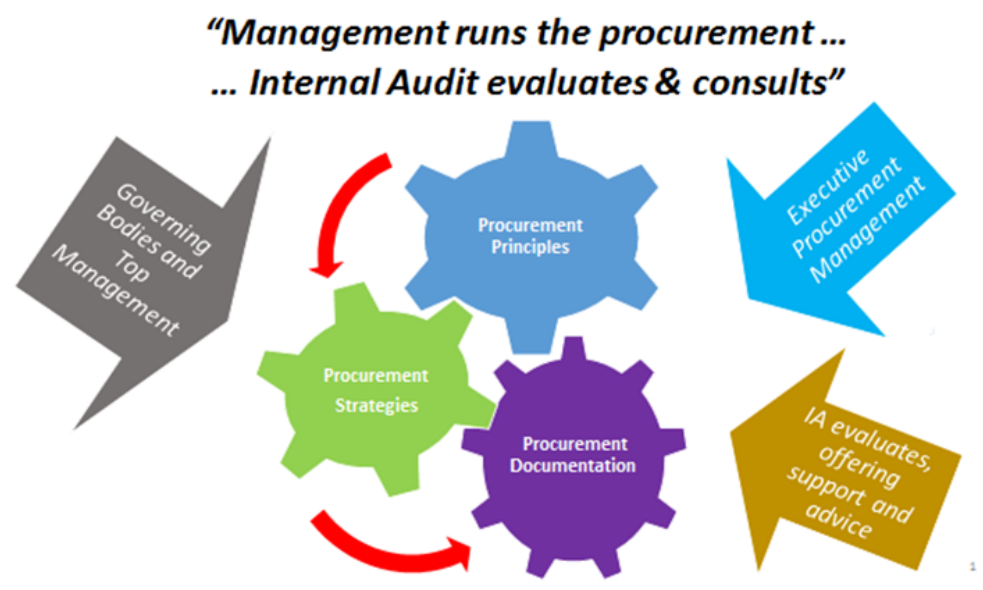

Figure 1: Governance structure of procurement processes (made by the authors) 


\section{Characteristics of Internal Audit Interaction with Procurement}

Although IA consulting is still a recent endeavor, as it was aforementioned, under the auspices of the Institute of Internal Auditors (IIA) and the masters of its evolution, there are organizations that have fully adopted the new IA definition along with its policies and practices implications. As case studies spearheading towards this direction we may recall plenty of European Union related Agencies, Institutes and Institutions, which more or less perform IA advisory. For instance, particularly for the procurement consulting the responsible officers may request the Internal Auditor, under certain circumstances like prior to launching a Call for tenders or awarding a contract, to express advice on the compliance and/or the improvement of the respective procedures. The recommendations expressed by the Internal Auditor carry of course the disclaimer that they shall not affect the full responsibility of the authorizing and/or responsible officers for the procurement procedure; they shall not also prejudice the auditor's opinion during possible subsequent audit performed on the same subject.

The advice provided by the IA in these occasions, on one hand, refers to the compliance with the requirements set out in the relevant procurement rules, however it does not enter into the supplies or services technical merits. In this context, acknowledging the full responsibility of the procurement managers along with the auditors' independence, the consulted and recommended points are not binding for the authorizing and/or responsible officers. Generally, the added value of internal audit consulting on procurement is recognized by the other administrative departments working at the Organization, as long as it represents a line of defense against adversary events which may compromise the soundness and accountability of the organization's contracting engagements. This fact may be also realized through a reverse assumption of the possible financial losses or the legal issues that might have taken place if no early advice or consulting discussion had been launched and adopted.

\section{Strategic Procurement Challenges}

In the above described schema of periodic and cyclic interactions among principles, strategies and standardized documentation, public regulators and decision making boards have the oversight, but internal auditing takes over the responsibility to evaluate and support when necessary, offering continuous consultation. The modern procurement strategies are developed to facilitate productivity and global efficiency imperatives. The free market competition principles determine a framework of equality and fairness balancing the performance maximization needs with rule of law and humanistic values. At the practical level then strategies and principles combined regulate and improve the operational documentation towards increased accountability, quality standardization and sound financial management.

The key processes that are identified as challenging the current procurement framework around the world are among others related with:

- outsourcing of operations for logistics savings and shortcuts,

- up scaling international market-shares in terms of quantity and quality,

- business continuity against interruptions and high-tech threats,

- contracting typology transformation,

- upgrading computer-aided anti-fraud policies.

It is remarkably interesting that the strategic procurement elements stated above converge, in other words, they are all interconnected implying integrated enterprise solutions. In this line the growth of management decentralization developed outsourcing solutions that progressively reinforced market globalization. Business continuity, threatened by over-exposure due to outsourcing and globalization, required high technologies safeguards and quality standards applied and respected. The contracting then evolved into new formats like the concessions, the mixed, framework and leasing agreements out of the traditional box of procurement natures clearly classified in the past as supplies, services and works. Public sector struggles to assimilate performance and reporting characteristics initially developed by the private one, while they 
nowadays share almost similar principles, procedures and documentation traits in favor of accountability, transparency and performance optimization objectives, despite they start from and end up to different motives, interests and destinations respectively.

\subsection{A global projection of outsourcing}

Over the past several decades, international or global sourcing has been a major trend. The so called market globalization, the expanding interdependence among national economies, the international business competition, the progress of information and communication technologies as well as the fall of international trade barriers have driven many companies and in general economic operators to source from and offer goods and services abroad (Arnold 1999; Ellram et al., 2008 and Kotabe et al. 1990). This development has attracted increasing interest from both academic and managerial circles (Benito et al., 2013 and Lahiri et al. 2011). The number of organizations that outsource multiple business processes to external suppliers has been increased all over the world. The business process outsourcing (BPO) market, beyond the traditional manufacturing outsourcing, had globally reached a value of over $\$ 300$ billion in 2012, representing a broad range of administrative, logistics and advisory activities, while the overall volume kept growing at rates of approximately $25 \%$ per year afterwards (Sartor et al. 2014).

Outsourcing is relieving business pressure to adjust with erratic work demands in dynamically changing markets. When a process is consistent and repeated across a business sector, outsourcing can sufficiently detail the procurement specifications. Contracting then is being developed as a decentralized project that can be standardized into logical procedure steps, easily communicated, monitored and executed. Nevertheless, the main trigger for the BPO expansion was mainly the objective to reduce costs or access specialized skills and expertise; eventually outsourcing further evolved especially due to the information technology highly increased networking capabilities (Lacity et al. 2013).

From the procurement point of view, outsourcing results in "calls for tender" minimizing transaction costs while maximizing the best value for money. In the context of transaction costing (TCE), any single transaction turns to be the basic unit of evaluation and procurement decision making. The dilemma between "make or buy" was initially referring to cost economizing purposes, as we mentioned before. However, the contracting needs also include long term benefits that may not seem economical at the first place. The quest for quality products and services outside an organization's premises assign additional attributes over the transactions, emphasizing on whether externalizing businesses preserves continuity and guarantees added value more than internalizing efforts and investments. The answer is not in favor of outsourcing by default, since it depends on specific business parameters and surrounding circumstances. The basic tendency though is that a globalized economy, due to high efficiency requirements, is more effectively served by outsourcing contractual relations, multilateral dependencies and governance favoring a progressive transition from simple market exchanges to hybrid and matrix contracting formats (Williamson 2008).

The new approaches to the organizational procurement decision making prioritize quality standardization rather than simple cost reduction. While outsourcing plays a significant role in cost savings by focusing on core expertise, there are still market niches that avoid outsourcing for confidentiality reasons like the research development laboratories or the military headquarters performing top secret operations that cannot be shared with competitors or adversaries. In the same risk-based approach, management should be aware of the risks related to the outsourcing of engagements (information control, data protection, etc.) affecting process of personal data. For instance, services like the Information \& Technology (IT) Helpdesk may be much more easily outsourced, since they are usually peripheral and related to end users, rather than the databases management or the programs development. Outsourcing the latter ones usually results in numerable case studies of entities which shared critical information with unreliable partners, suffering several forms of vulnerability, exploitation, intellectual property frauds and thefts (Schniederjans et al. 2015).

"Insourcing" critical tasks and resources may not be the proper decision in terms of efficiency, but it usually reduces the exposure of the organization to external risks and threats. Procurement 
decisions, therefore, should be taken based not only on the need for cost reductions but also towards mid-term value contribution as well as long-term business continuity and strategic objectives achievement (McKenna et al. 2008).

The globalization perspective of outsourcing drives nowadays to the emigration of projects towards high and low wage economies. The implications of such a workforce mobility are related with cultural diversity and sustainable development around the world. We can see in our daily lives a huge intersection of cultures intruding purchasing \& contracting rules and practices. On the other hand, language burdens appear and occasionally distort the competition, but the globalization process has found the ways to internationalize communication, negotiations and procurement (Eroglu et al. 2005). In the context of procurement advisory, it has been practically observed a tendency of some managers to dismiss the tender documentation international versions. Given though that contracting authorities progressively adopt international character, especially across the EU markets, it takes time to cultivate understanding and trust. Outsourcing definitely works for the promotion of an effective dialogue by integrating the beneficial aspects of diversified and specialized markets, however regulators are usually challenged to acknowledge and manage the inherent conflicts identified in social disparity or politics clashes among national and international stakeholders (Salerno 2004).

\subsection{Procurement as a guarantee of Business Continuity}

Taking into account the impact that plenty of contracted services exert upon the continuity of critical organizational operations, it is highlighted how important may be for both public and private sector entities to require from the tenderers, in the context of their Internal Control Systems, formal contingency planning, ensuring as much as possible the sustainability of the specific operations acquired at any moment in case of force majeure, absences, disruptions, etc. Naming the need for backup plans reinforces the organization's effectiveness towards business objectives achievement (Cendrowski et al. 2009).

On the side of the procurement planning, purchasing managers must additionally identify corporate social responsibility (CSR) implications of their decisions, as well as strategic environmental contingencies that should be integrated into the acquisition processes and procedures. Environmental monitoring consists of identifying factors which are potentially contributing into the realization of risks. It also entails an examination of interactions between product/service and resources management (Spekman 1981). In such a context of driving the design for procurement (DFP) the managers should take advantage of numerable modern managerial tools that guarantee operational continuity, like standardization, enterprise resources management (ERM), e-procurement, outsourcing, lead time reduction, environmental sourcing, etc. (Brewer et al. 2017).

The main concern with organizations which are either material or labor intensive is the integration of purchasing decisions into the overall strategies serving the organization's vision and missions. The need for the development of a contingency theory or guidelines for selecting procurement strategies requires specialized and improved procurement skills, especially since, in the short future, businesses are world-wide expecting to meet shortages of funds and resources (Adamson 1980).

Numerable successful procurement examples demonstrate how tenderers offer backup and recovery solutions, while contracting authorities develop procurement models and support methods that expand and up level an organization's image and performance potential. It is well known, for instance, how the Fujitsu Research Institute (FRI) deployed Fujitsu's Business Continuity Management (BCM) practices in September 2005. They established an institute dedicated to promoting BC planning monitoring critical products and services. Their procurement office examined a range of issues in regard with interactions related to suppliers, particularly quality and cost agreements, running continuous dialogue for improvement and procurement optimization.

A year later no tenderers were accepted unless they had submitted answers on questionnairebased surveys referring to BCM capabilities. The procurement partners were afterwards offered Supply Chain Continuity Assessment services based on specifications and requirements 
successfully applied in previous partnerships, in order to leverage future supplies and meet the high standards of excellence as they were benchmarked in this collaboration model. Fujitsu's own procurement office included in its jobs description a basic assessment of suppliers' business continuity, while customized consulting was available for the mutual benefit of both the contracting authority and its multiple contractors (Japan Corporate News Network 2007).

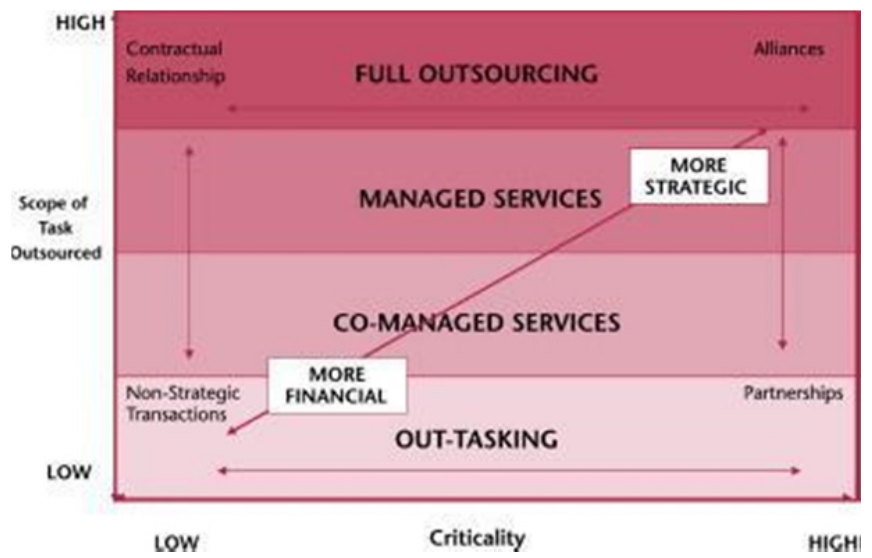

Figure 2. The interaction between outsourcing and criticality of tasks, which is also a driver for the procurement policies (Gunasekaran et al. 2015)

In this way, procurement organization is a catalyst for balanced internal coordination and external cooperation. The figure above (Figure 2) shows the interaction between outsourcing and criticality of tasks, which is also a driver for the procurement policies since no outsourcing can be launched without the deployment of relevant contracting decisions, plans and implementation. The implied interoperability among strategic management and procurement may be further enhanced by modern evaluation and control techniques like facilitated networking, control self-assessment and corporate governance; right at this point internal auditing may offer added value on the configuration of effective contracting review and compliance (Westland 2007).

The procurement process is cyclical in the sense that it initiates a dialogue, a "journey" of information, goods, works and/or services exchanged between contracting authorities and market contractors. Before the procurement launch, its organization reflects the risk appetite of an organization as well as the time and spatial relationships with the stakeholders and partners from local to global, from national to international, from restricted to open procedures, from centralized to decentralized and vice versa. After the procurement procedure is launched and contracts have been awarded, the impact of contracts execution is critical on the sustainability of the stakeholders' value drivers. No matter if the operations refer to public or private sectors, the common ground of procurement managers, reviewers and advisors should be the focus on creating and safeguarding value for shareholders and citizens respectively.

\subsection{The significance of Intellectual and Property Rights}

Intellectual Property Rights are legal rights related with the protection of intellectual activity in industrial, scientific, literary and artistic fields. It is being noticed that the evolution of IT has directly multiply the quantity and importance of the respective contracts' sections. It is an optional but quite usual best practice for the procurement managers to set a contracting clause clarifying the ownership status whenever contracting is related to software programs application, development or implementation. In multiple occasions, the documentation of such calls for tenders usually describes access rights' details, but it does not take advantage of that specific potential to specify the legal rules for monitoring any applied software IPRs. This may confuse tenderers or could 
expose the organization to risks regarding the ownership/sponsorship/management of IPRs.

The idea behind the property rights approach is to provide not only guarantees but also incentives for advanced and/or prototype productive activities, because any developer, inventor or designer makes steps forward as long as it is worthy to proceed in terms of respect, rewards and recognition (Parcu et al. 2017). They were originally introduced to promote the progress of science and fine arts. Especially for the software intellectual property rights their analysis is remarkably complicated, including ownership, sponsorship, management, exploitation of pre-existing archiving programs, third parties involvement, etc., and that is the reason why we all, as final software users, receive those long disclaimers and users' terms to undersign before any operation (Lambert 2012).

All the above IPR analysis is also relevant to the improvements of the procurement procedures and documentation over the last years. However, we may consider it mostly as a strategic approach of business decision making, because first of all IT has turned to be the sine qua non organizational backbone of all the organizations, and secondly, because of the fact that management boards highly realize how broadly both public entities and corporate businesses are being bound to international IT de facto monopolies, experiencing critical dependencies and challenging the traditionally, especially in the public sector, conservative procurement legal and regulatory frameworks. For example, the latter may hardly stipulate contract duration longer than seven years, while operating systems and applications are being built nowadays towards a development and operation cycle of the double at least prospective.

That explains the increase of the public sector requests for exceptional proceedings with negotiated procedures to renew via direct awards the contracts for supply, implementation, customization and integration of the IT Systems in favor of the current suppliers. It does not seem as a best practice, except if the long lasting renewals are excused under the preconditions that the contracts contain adequate clauses on transfer/licensing of intellectual property (IP) rights in favor of the contracting authority. The long term solution is indeed strengthening the organization's grasp on the IP rights created in the context of IT service contracts. Top management and stakeholders should be aware that they are organizationally dependent on a single economic operator. This dependency should be reduced by increasing the organization's share/ownership of the relevant IP. The IP terms recommended could also be discussed with the contractors/companies as new contracting terms. Otherwise, the contracting institutions will be somehow, more and more as the time goes on, "trapped" in the above mentioned dependency on a single provider, facing the risks:

- of being de facto impotent of running a procurement competition in the future,

- of having severe vulnerability, damages and losses in case of the unique company's operations disruption,

- of having pressure from the economic operator on increased charges (compared to other similar companies' charges).

The contracts extensions in discussion are usually based on de facto monopoly and/or repetition of similar works and infrastructure investments. The disadvantage though is that the de facto monopolies can be questioned due to the abundance of other companies/providers of similar IT services and IP protection.

\subsection{Contracts typology transformation}

Framework Contracts. Over the last decades the traditional procurement procedures, based on the philosophy of producing single and direct contract with well-defined contracting actors and strict terms, have been under pressure for reform due to the market needs not only for effectiveness and efficiency but also for speed and agility. The corporate world followed by governments and international organizations has developed alternative forms of contracts, like for example the framework contracts, which indeed drive the otherwise heavy procurement bureaucracies to balanced solutions, fulfilling both the needs for accountability and flexibility. In order to prevent any misunderstanding around the definition of the so called framework agreements/contracts, the main respective typology utilized in public organizations should be further discussed. More specifically, a Framework Contract has the characteristic of being signed as an introduction to be followed up by 
multiple secondary orders/contracts. The implementation of the latter is based on direct application of the terms envisaged at the "umbrella" framework contract (FWC). This kind of contracting is useful for repetitive needs, where the contracting authority does not specify the exact time and volume of delivery.

However, it is not enough anymore for a call for tenders' documentation to abstractly mention the Framework Contract (FWC) type in title, but it should also define whether it refers to specific versions like:

- a Single Framework Contract (one economic operator, exclusivity),

- a Multiple Cascade FWC (at least three ranked winners, requests follow their order),

- a Multiple FWC with reopening, (at least three winners, simultaneous requests).

One point related with FWCs that is worthy to be highlighted concerns the respective FWC award criteria; they should be framed by measurable and quantified criteria/ranking rules, explaining according to which standards or documentation a company may be graded "excellent, good, adequate or inadequate". This remark is of great importance particularly in the case of the "FWC in cascade" because of their particularities that bring multiple winners into direct and continuous comparison and ranking among each other. For instance, if interviews of personnel are involved in the evaluation of the technical offers, it is advisable for the tender specifications to explain in detail the scoring of the personnel criteria required (e.g. how many points for $\mathrm{X}$ number of working experience years stated in the CVs, how many points for specific technical specialization or training courses, etc.)

Mixed contracts. Plenty of calls for tenders currently describe both services and supplies, deliverable in the context of a Mixed Procurement. In these occasions the documentation should clarify certain needs, subject/objects, specifications, quality and quantity of the items in need to be purchased, as well as the relevant cost estimates (Pitt et al. 2014). Therefore, the ratio of services/supplies values, along with the allocation of expenditure for the contract execution, needs to be explicitly defined, and the tender should present data driving to the appropriate comparison between the values of services versus supplies, respectively (Chaudhry at all. 2012). Such a breakdown based on the nature of the procurement parts is mainly required in order to classify the overall mixed procurement as a service or supply one, which results in the application of different sets of competition rules, specifications and model contracts.

Concessions. Another powerful and revolutionary tool that tends to prevail in the modern procurement world is the so called concessions. Usually, it is the same or similar legislative framework that may apply at a wide range of outsourcing a simple canteen up to the real estate and building management of constructions, premises and facilities. On one side, the scope is extremely wide, reflecting contract values of a few thousands up to millions of euros. On the other side, it may facilitate a "circumvention" of the strict procedural set up concerning the open or restricted procurement procedures towards public contracts. In this way it may give flexibility but escapes control mechanisms. Additionally, the negotiated procedures, mostly applying when concessions are launched, do not require further controls and approval opinions. By definition, the ConcessionContracting Authority will give up the risk but also the control in favor of an operator/concessionaire, which seems like the most advanced version of outsourcing, carrying both its pros and cons discussed earlier.

In the public sector, such a reduction in an entity's operations and controls needs definitely increased assurance that the concessions will not eventually harm public interests or organizational reputation. For example, several public institutions and agencies lately were deeply concerned with older decisions to replace their whole ICT systems with the services of private companies. The costs savings were remarkable, but the data protection regarding the operations was diminished due to sharing critical information with any concessionaire involved. For the above reasons, it is advisable for the Concession-Contracting Authorities to safeguard, in consultation with internal auditors and legal advisors, their interests through preliminary impact assessments, performed before the launching of concession award procedures, in order to assure that the option of a concession is not jeopardizing accountability, transparency or other organizational policies and objectives. 


\subsection{Corruption in the procurement field}

Last but not least among the current strategic challenges met by procurement managers is the corruption threat. This is a permanently applying risk against legal and ethical organizational behaviors, but its reflection nowadays has taken high technology formats that have tremendously multiplied the possible catastrophic consequences of fraud schemes and relevant discrepancies. Numerable analysts present evidence of policies which avoid open competition in procurement based on the manipulation of procurement values. In the context of several policy reforms, public bodies enjoy the autonomy to pre-select and invite directly potential contractors submitting tenders below discretionary thresholds. The bunching of procurements just a few euros below the thresholds is a usual practice for splitting up the high value contracts in order to avoid publicity and controls. It has been also reported that contracts awards are allocated to anonymous and irrelevant firms, which hide real owners as well as other parties involved (Palguta et al. 2017). On the other side, the compliance and control checklists highly contribute in favor of anti-corruption risk management in procurement, as long as they prevent or detect fraud incidents. In this way procurement managers are facilitated towards reporting irregularities resulting in transparent and accountable procurement.

The so called red flags are also really useful as alarming signals and evidences of possible fraud schemes. The presence of a red flag does not mean that a fraud event exists, but that a specific area of activity needs additional monitoring in order to avert or detect a potential fraud. Some behavioral patterns, attitudes and practices are red flags that could signal irregularities or fraud. The anti-fraud examiners find their way through observations that may seem of minor importance, they, however, offer a reliable starting point for the investigation. For instance, an unexplained favorable treatment of an applicant/contractor over a period of time, a bidder's main area of activity according to its website being different than the scope of the tender or invoices issued at the end of the year but carrying low serial numbers are some of the usual tips raising a red flag. Similar practices may happen in a series of operations but usually the championing areas are recruitment, travel allowances, removal costs, medical expenses, unemployment expenses, etc.

The latest results of the relevant research state that there is a direct relationship between the states' effectiveness against procurement corruption and the managerial tendency to expand the use of e-government. Towards this direction, decision makers should popularize electronic signatures, which is a prerequisite for secure e-procurement. Therefore, the funding offered by the European Union to implement this technology is being increased, monitoring almost all the way of procurement logistics and financial chains, as for example it is depicted in the flowchart below (Fig. 3). Furthermore, special bonuses or benefits could be awarded to private sector official or business operators using Information and Communication Technologies during their interaction with the governments. The increased traceability of transactions in the client-administration relationship results in reduced corruption as well as in enhanced productivity (Szopinski et al. 2017).

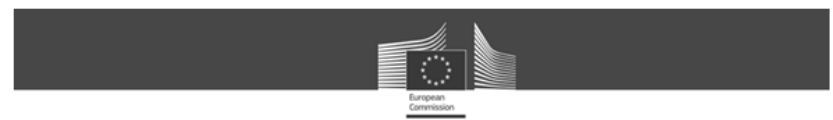

\section{e-Procurement development status}

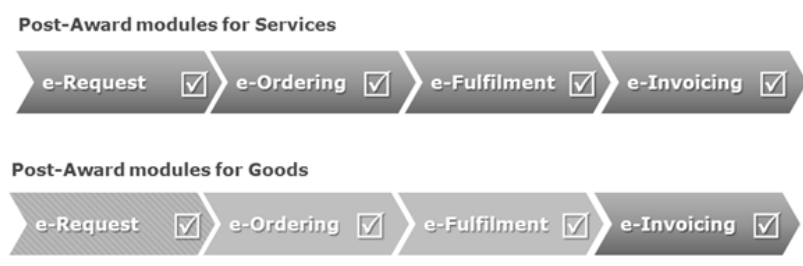

Figure 3. European Commission E-Procurement development status (Slide Player, 2014) 


\section{Conclusions and Business Implications}

In recent years the procurement outsourcing along with several forms of sub-contracting and joint ventures have become an increasingly popular method of running public entities and/or publicly held corporations, shaping governance principles and restructuring the future of corporate responsibility for both the private and the public sector (Hiroyuki et al. 2010). The procurement collaborations in the context of "just in time" logistics systems, where the contractors progressively co-operate sharing variable levels of risk responsibility with the contracting authorities, have upgraded the strategic significance of acquisition management systems. The speed and efficiency with which a properly planned procurement cooperation can be effected creates unusual till recently incentives for the use of the tender offer techniques as alternative business solutions against cumbersome and often more expensive traditional competition formats. (Aranow et al. 1972)

Given that the respective organizational universe rushes through major changes, the volatility of procedures may also be considered as a vulnerability, undermining sustainability and accountability of decisions, processes and procedures. Control mechanisms have to be accordingly adapted. For instance, the sustainability of public procurement (SPP) must be a priority in theory and practice as a means for the governments for ensuring that contracting contributes to broader environmental and social policy goals like reduction of greenhouse gas emissions, promotion of employment, social inclusion and equality, etc. (Sjåfjell et al. 2015).

The interaction between procurement managers and Internal Audit Consultants in the methodological context described above results in remarkable organizational benefits. Procurement management may reasonably ensure a coherent and streamlined workflow which is characterized by the fact that the objectives described are concrete and achievable, risks are well considered and prioritized. In the meantime, the progress of the procurement objectives' achievement is monitored, evaluated and updated with an approach following the so called SMART methodology, i.e. on the basis of specific, measurable, timely updated and relevant data (Dlabay et al. 2016).

\section{IMPACT OF COLLABORATIVE AUDITING}

\section{Over time, collaborative auditing will increase value for the business while reducing actual gaps and risks using less instrusive methods.}

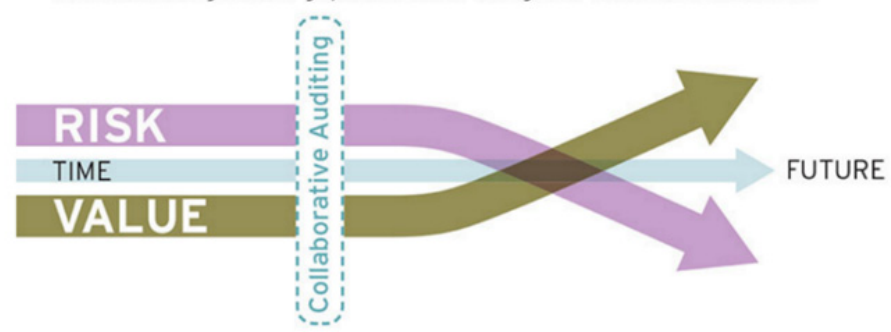

Figure 4. The added value of a collaborative and non-intrusive impact auditing, see (D' Cunha 2013)

In terms of policy implications as well as for further research recommendation, the evolution of procurement decision making and administration has highly turned to technology systems and computational analytics that measure the performance and predict risk levels driving to respective e-procurement activity (Bamberger 2010). The regulators have welcomed the move to technology, but there are always present and usually ignored perils, accountability challenges posed by the technologies of control, therefore both procurement officials and auditors should be in an increased readiness to recommend reform measures and revisiting the governance of risk.

The underlying philosophy of the modern Self-Assessment based management, as it is shown in the figure above (Figure 4) and recommended by internal auditing, has profoundly positive consequences especially for the procurement governance. Under this point of view auditors may 
facilitate the contracting authorities' empowerment through supporting their assessment capabilities and risk-based decision making. The model works metaphorically like a "medical self-diagnostic" system against any kind of procurement frauds and scandals. This model is characterized by the fact that managers identify and mitigate their weaknesses long before they suffer organizational "health" problems and need an extended and inclusive remedial treatment (Alles et al. 2008). The configuration of an integrated and continuous auditing approach over purchasing and contracting is an ambitious auditing vision that is highly expected to recover the troubled relationship between managers and auditors by improving mutual understanding and collaboration towards the soundness and effectiveness of procurement procedures.

\section{References}

Adamson, John (1980), "Corporate long-range planning must include procurement" Journal of Purchasing and Materials Management, Vol. 16, No 1, 25.

DOI: 10.1111/j.1745-493X.1980.tb00012.x

Albano, Gian Luigi - Caroline, Nicholas (2016), The Law and Economics of Framework Agreements: Designing Flexible Solutions for Public Procurement, Cambridge, Cambridge University Press

Alles, Michael George - Alexander Kogan - Miklos Alex Vasarhelyi (2008), "Putting Continuous Auditing Theory into Practice: Lessons from Two Pilot Implementations", Journal of Information Systems Vol. 22, No 2, pp. 195-214 https://doi.org/10.2308/jis.2008.22.2.195

Alpigiano, Carlotta - Georgios Baltos (2017), "From audit-phobia to shared governance philosophies: librarians meet auditors at the European University Institute", The 9th Qualitative and Quantitative Methods in Libraries International Conference (QQML2017), Conference proceedings, Limerick, Ireland, pp. 51 - 63.

Aschauer, Ewald - Matthias, Fink - Andrea, Moro - Van Bakel-Auer - Katharina, and Bent - WarmingRasmussen (2017), "Trust and Professional Skepticism in the Relationship between Auditors and Clients: Overcoming the Dichotomy Myth", Behavioral Research in Accounting Vol. 29, No. 1 p . 19. https://doi.org/10.2308/bria-51654

Boecker, Corinna - Julia Busch - Oliver Bussiek (2008), Internal Audit Handbook Management with the SAP Audit Roadmap, Springer, Verlag, Berlin, Heidelberg

Bovis, Christopher (2012), EU Public Procurement Law, New York, Edward Elgar

Brewer, Barry - Arnette, Natalie (2017), "Design for procurement: What procurement driven design initiatives result in environmental and economic performance improvement?" Journal of Purchasing and Supply Management, Vol. 23, No 1, 28-39.

Cendrowski, Harry - Mair, William Charles (2009), Enterprise Risk Management and COSO: A Guide for Directors, Executives and Practitioners, New York, Wiley.

Chatterjee, Sandra - Slotnick, Stephen Andrew and M. J. Sobel, Michael John (2002) Delivery guarantees and the interdependence of marketing and operations. Production and Operations Management Vol. 11, No. 3, pp. 393-410.

Chaudhry, Peggy Ellen - Alan Zimmerman (2012), Protecting Your Intellectual Property Rights: Understanding the Role of Management, Governments, Consumers and Pirates, Springer Science \& Business Media, Berlin

Chêne, Marie (2010), Examples of procurement compliance checklists, U4 Expert Answers, Transparency International, Washington

Cheri O'Neil, (2015). 10 Professional Skills Accountants Want Most, Robert Half - Finance \& Accounting, the link: https://www.roberthalf.com/finance/blog/10-professional-skills-accountants-want-most (Accessed on: 21.08.2017).

ClientEarth - Justice for the Planet., (2011). Identifying Opportunities for Sustainable Public Procurement Briefing Series- Briefing No. 3: The guiding principles of public procurement transparency, equal treatment and proportionality The link: https://www.clientearth.org/reports/procurement-briefing-no-3-guidingprinciples-equal-treatment-transparency-proportionality.pdf (Accessed on: 21.08.2017).

Colombia University, (2008). Finance Gateway Procurement, New York, the link: https://finance.columbia.edu/procurement/lifecycle (Accessed on: 21.08.2017).

Bosworth, Derek Lewis (2014), Intellectual Property Rights, Elsevier, Amsterdam, p. 56.

Dlabay, Lee, Burrow, James and Kleindl, Brad, (2016), Principles of Business, Mason, Cengage Learning, Mason.

Eroglu, Sevgin - Corliss Green Thornton and Danny Bellenger (2005), "Impact of Ethnicity on Management and Channel Building in Minority Enterprises" Journal of Marketing Channels Vol. 12, No 3, pp. 27-52. doi: $10.1300 / J 049 \mathrm{v} 12 \mathrm{n} 0303$.

European Commission, (2013). EU Competition Law - Rules Applicable to Antitrust Enforcement, Volume I: General Rules WIPO, 
http://www.dcmsme.gov.in/emerge/website_material_on_ipr.pdf (Accessed on: 21.08.2017).

Finance (IAC) Department (2012), Hand Book of Guidelines on Internal Audit, IAC, Washington.

Fujitsu enhances business continuity management in procurement; supports suppliers' BCM readiness with assessment and other assistance. (2007, Aug 21). JCN Newswire - Japan Corporate News Network Retrieved from https://search. proquest.com/docview/467522443?accountid=33980

García, Nazario - Javier Puente - Isabel Fernández, and Paolo Priore (2013), "Supplier selection model for commodities procurement. Optimised assessment using a fuzzy decision support system", Applied Soft Computing “Vol. 13, No. 4, pp. 1939-1951. doi: http://dx.doi.org/10.1016/j.asoc.2012.12.008.

Gehring Robert Andrew (2002), Software Development, Intellectual Property Rights, and IT Security, the First Workshop on Economics and Information Securit

Giese, Joan L. - Joseph A. Cote (2002). "Defining Consumer Satisfaction", Academy of Marketing Science Review, Vol. 2, No. 1. 1 - 24. doi=10.1.1.195.6980

Gunasekaran, Angappa - Zahir Irani - King-Lun Choy - Lionel Filippi and Thanos Papadopoulos (2015) Performance measures and metrics in outsourcing decisions: A review for research and applications", International Journal of Production Economics Vol. 1, No. 2, pp. 61:153-166. doi: http://dx.doi.org/10.1016/j.ijpe.2014.12.021.

Harkiranpal, Singh (2006). The Importance of Customer Satisfaction in Relation to Customer Loyalty and Retention, Dehli, UCTI Working Paper

Hiroyuki, Odagiri - Akira Goto - Atsushi Sunami - Richard R. Nelson (2010), Intellectual Property Rights, Development, and Catch Up: An International Comparative Study: An International Comparative Study, Oxford, OUP Oxford

Ho, William - Xiaowei, Xu and Prasanta K. Dey (2010), "Multi-criteria decision making approaches for supplier evaluation and selection: A literature review", European Journal of Operational Research Vol. 202, No. 1, pp. 16-24.

doi: http://dx.doi.org/10.1016/j.ejor.2009.05.009.

Ilieska, Karolina (2013), "Customer Satisfaction Index - as a Base for Strategic Marketing Management", TEM Journal, Vol. 2, No. 4, 327-331. http://dx.doi.org/10.1080/09652540010003663

Janet, Yoan - Murray, Emmanuel (1990), "Linking product and process innovations and modes of international sourcing in global competition: A case of foreign multinational firms" Journal of International Business Studies, Vol. 21, No 3, pp. 383-408. https://doi.org/10.1057/palgrave.jibs.8490339

Jason Westland., (2007), The Project Management Life Cycle: A Complete Step-by-step Methodology for Initiating, Planning, Executing \& Closing a Project Successfully, London, Kogan Page Publishers

Jedrzejowicz, Pawel - N.T. Nguyen, R.J. Howlett, and L.C. Jain (2010), "Agent and Multi-Agent Systems: Technologies and Applications: 4th KES International Symposium" KES-AMSTA 2010, Gdynia, Poland, June 23-25, 2010. Proceedings: Springer.

Jeynes, Jacqueline (2002), Risk Management 10 Principles, Oxford, Butterworth - Heinemann

K, H, Spencer Pickett., (2005). The Essential Handbook of Internal Auditing, John Wiley \& Sons, Chichester,

Knight, Louise - Christine Harland - Jan Telgen (2012). Public Procurement: International Cases and Commentary, Routledge, London

Lacity, Mary Carla - Leslie Pipa Willcocks (2013), "Outsourcing business processes for innovation" MIT Sloan Management Review, Vol. 54, No 3, 63-69. https://doi.org/10.1108/SO-11-2013-0023

Lahiri, S. and Kedia, B.L. ( 2011 ), "Co-evolution of institutional and organizational factors in explaining offshore outsourcing" International Business Review, Vol. 20 No. 3, pp. 252 - 263 https://doi.org/10.1016/j.ibusrev.2011.01.005

Lambert, Miss Jane (2012), Enforcing Intellectual Property Rights: A Concise Guide for Businesses, Innovative and Creative Individuals, Gower Publishing, Farnham, pp. 27-37.

Legal and Risk Branch - Division of Services and Resources (2015), Adelaide, University of Adelaide, Legal and Risk Branch - Risk Management Handbook

Lember Veiko - Rainer Kattel - Tarmo Kalvet (2013), Public Procurement, Innovation and Policy: International Perspectives, Springer Science \& Business Media, Berlin

Lynch T, Jorge Angel (2013), Public Procurement: Principles, Categories and Methods, Lean Publishing, Victoria, British Columbia, Canada

McKenna, David - Derek H.T. Walker. (2008), "A study of out-sourcing versus in-sourcing tasks within a project value chain" International Journal of Managing Projects in Business, Vol. 1, No 2, 216-232. https://doi.org/10.1108/17538370810866340

Menell, Peter Stephen (2007), Intellectual Property and the Property Rights Movement, Research \& Development, Washington

Ministry of Environmental Protection and Regional Development. (2017). A Green Public Procurement (in Latvian: Zaliais publiskais iepirkums), the link: http://www.varam.gov.Iv/lat/darbibas_veidi/zalais_publiskais_iepirkums/ (Accessed on: 21.08.2017). 
Nagy, Albert Leonard - William J. Cenker (2002), "An assessment of the newly defined internal audit function", Managerial Auditing Journal Vol. 17, No. 3, pp. 130-137. https://doi.org/10.1108/02686900210419912

NEC (2005), NEC3: Framework Contract: Guidance Notes and Flow Charts, Thomas Telford, Bredford

Palguta, Ján - Filip Pertold (2017), "Manipulation of Procurement Contracts: Evidence from the Introduction of Discretionary Thresholds", American Economic Journal. Economic Policy Vol. 9, No. 2, pp. 293-315. doi: http://dx.doi.org/10.1257/pol.20150511.

Parcu, Luigi - Giorgio Monti - Marco Botta (2017), Abuse of Dominance in EU Competition Law Emerging Trends, Elgar, Cheltenham

Pitt, Sally-Anne - Michael Pitt, (2014), Internal Audit Quality: Developing a Quality Assurance and Improvement Program, John Wiley \& Sons Inc, United States, New York, pp. 156-157.

Rhee, Seung-Kyu - June-Young Rha (2009), "Public service quality and customer satisfaction: exploring the attributes of service quality in the public sector." The Service Industries Journal Vol. 29, No. 11, pp. 14911512. doi: $10.1080 / 02642060902793441$.

Salerno, David (2004), "Outsourcing: Wagering protection" Journal of Epidemiology and Community Health, Vol. 58, No 5, 373. . http://dx.doi.org/10.1136/jech-2016-208671

Sartor, Marco - Guido Orzes - Guido Nassimbeni - Fu Jia, and Richard Lamming (2014), Purchasing and Supply Management Vol. 20, No 1, pp. 1-17. http://dx.doi.org/10.1016/j.pursup.2013.09.002.

Schniederjans, Michel Jacob - A.M. Schniederjans, and D.G. Schniederjans (2015), Outsourcing and Insourcing in an International Context: Taylor \& Francis.

Sjafell, Beate - Anja Wiesbrock (2015), "Sustainable Public Procurement Under EU Law" Cambridge, Cambridge University Press

Slide Player (2014), CEN/BII Seminar, link http://slideplayer.com/slide/4575929/ (Accessed on: 21.08.2017).

Spekman, Robert (1981), "A strategic approach to procurement planning" Journal of Purchasing and Materials Management, Vol. 17, No 4, 2. doi:10.1111/j.1745-493X.1981.tb00038.x

Szopinski, Tomasz, and Marcin W. Staniewski (2017), "Manifestations of e-government usage in postcommunist European countries." Internet Research Vol. 27, No. 2, pp. 199-210. https://doi.org/10.1108/IntR-01-2015-0011

UNOPS, Procurement Advisory link: https://www.unops.org/SiteCollectionDocuments/Factsheets/English/Services/Procurement/Procurement_ Advisory_Services_EN.pdf (Accessed on: 21.08.2017).

Westland, Jason (2007). The Project Management Life Cycle: A Complete Step-by-step Methodology for Initiating, Planning, Executing \& Closing a Project Successfully, London, Kogan Page Publishers

Williamson, Oliver E. (2008), "Outsourcing: Transaction Cost Economics and Supply Chain Management" Journal of Supply Chain Management, Vol. 44, No 2, 5-16. doi:10.1111/j.1745-493X.2008.00051.x 